\title{
A EXPERIÊNCIA DO TEMPO \\ NOS ZOLLIKONER SEMINARE DE HEIDEGGER
}

\author{
Irene Borges-Duarte \\ Universidade de Évora
}

Numa carta a Karl Löwith de Agosto de 1927, Heidegger refere-se de veemente maneira ao que considera uma clara tergiversação do seu pensamento por aquele, dizendo:

A razão pela qual me tenho interessado tão pouco pela Psicanálise, é porque, fundamentalmente do ponto de vista filosófico e no que respeita aos problemas centrais, ela não me parece suficientemente relevante. Becker e você, em contrapartida, retorceram [umgebogen haben] desde o princípio a minha hermenêutica da facticidade à maneira da Psicanálise, forçando o meu trabalho numa perspectiva em que ele nunca se moveu.'

A designação "hermenêutica da facticidade" indica que a conversa já vinha de muito antes - "desde o princípio" [vom Anfang an], diz ele - quando, nunı primeira grande versão articulada em forma lectiva, em 1923, Heidegger apresentara a sua Ontologia - ainda sem apelido "Fundamental" - como uma Hermenêutica da Facticidade. Löwith, que não assistiu de forma directa a esse curso, teve, contudo acesso aos relatórios de um dos assistentes (Walter Bröcker), de que fez uma cópia (hoje conservada em Marbach), para seu uso pessoal. Terá sido com esse ponto de partida - podemos suspeitar-que, mais tarde, terá procurado entender Ser e Tempo. ${ }^{2}$

\footnotetext{
1 Veja-se a carta a K. Löwith de 20 de Agosto de 1927 , em resposta à deste de 2 de Agosto, reproduzida em "Drei Briefe M. Heideggers an K. Löwith", in Papenfuss \& Pöggeler, Von der Aktualität Heidegger's, Bd. 2, Frankfurt, Klostermann, 1992, 27-38.

2 Sein und Zeit [doravante SuZ], No correspondente velume da Gesamiausgabe [GA] Bd. 2, 1977; ed. de F.-W. von Herrmann, reproduz-se à margem a paginação da 7" ed: Tubingen, Niemeyer, 1953, pela que faremos as citações pertinentes.
} 
Ora, naquele último curso da primeira etapa de Friburgo, Heidegger introduzira, sem aparente pretexto histórico - isto é, sem o propósito de interpretação de nenhum autor, como até aí tinha sido o caso (com Santo Agostinho, com Aristóteles) - um novo sentido da "hermenêutica" enquanto "auto-interpretação da facticidade", ou seja como "tarefa de tornar acessível a si mesma a em cada caso sempre própria existência/aí-ser/Dasein". ${ }^{3}$ A novidade destas lições não reside só nem especialmente na temática - em que, numa linguagem ainda não definitiva, aparecem já os temas centrais de Ser e Tempo, mas que tinham ido surgindo pouco a pouco desde o Kriegsnotsemester ${ }^{4}$ de 1919 -, mas no facto da abordagem carecer de qualquer pretexto histórico-filosófico inicial, pelo que a designação "hermenêutica" se utiliza totalmente à margem do seu habitual contexto. É o ser humano quem, no seu viver quotidiano, necessita interpretar-se a si mesmo. Por isso, ele vê o seu passado à luz de como presentemente se encontra: no "hoje" [das Heute] dá-se o que passou - que é, em cada caso, o que lhe passou a cada um - num estar-interpretado [Ausgelegtheit] e só nesse estar-interpretado, que vem de atrás, podem surgir propósitos - Vorhabe, o ter prévio do que ainda não é - em que as coisas do mundo ganham sentido.

A tergiversação de Löwith, se bem que se compreenda que seja rejeitada por Heidegger, no uso do seu legítimo direito ante leituras espúrias, não parece, contudo, assim tão "retorcida". "Hermenêutica" fora, até então, ciência e arte da interpretação, quer de textos e dos seus autores, quer da lei. A deslocação do contexto de uso para a vida quotidiana ou existência fáctica, tacitamente projectiva, aproxima claramente a intenção filosófica de Heidegger da problemática freudiana, entendida não tanto no que tem de constituição de uma via terapêutica e da respectiva intervenção "interpretativa", quanto no que permite compreender do ser à maneira dos humanos. E Löwith - cuja obra Das Individuum in der Rolle des Mitmenschen, aparece em 1928, ${ }^{5}$ aprofundando num sentido antropológico a problemática da relação eu-outro - não foi, decerto, então, o único que se deu conta dessa proximidade.

Em 1942, Ludwig Binswanger, psiquiatra, inicialmente discípulo de Jüng, que o apresentou a Freud, de quem se aproximou, foi o primeiro a conceber uma forma de enquadramento do trabalho psicoterapêtico no que chamou uma Existenzialanalyse, cujas coordenadas procurou explicitamente em Ser e Tempo de Heidegger, embora também mencione a importância da fenomenologia husserliana e da concepção dialógica de Martin Buber, sem se esquecer de mencionar o trabalho de Löwith. A sua obra Gundformen und

3 "Die Hermeneutik hat die Aufgabe, das je eigene Dasein in seinem Seinscharakter diesem Dasein selbst zugänglich zu machen..." Veja-se Heidegger, GA 63, 1988 (ed. K. BröckerOltmanns): Ontologie - Hermeneutik der Faktizität, SS 1923, 14 ss.

${ }^{4}$ Heidegger, GA 56/57, 1987 (ed. B. Heimbüchel): Zur Bestimmung der Philosophie, KNS 1919.

${ }^{5}$ Löwith, K., Das Individuum in der Rolle des Mitmenschen, 1928. 
Erkenntnis menschlichen Daseins ${ }^{6}$ (1942) poderia figurar como modelo do que poderia ser o enriquecimento da meditação surgida da prática médica mediante a reflexão filosófica. Servem de base a essa elaboração transversal as problemáticas centrais da obra de 1927: o ser-no-mundo enquanto cuidado (Sorge) e enquanto estar-ocupado (besorgen), na sua espacialidade e na sua temporalidade, embora ambos os conceitos - como Heidegger dirá mais tarde - não sejam compreendidos com toda a amplitude e profundidade que Heidegger lhes dá. Na verdade, se, para este, o cuidado qua temporalidade constitui o ser do Dasein, para Binswanger só no amor há autêntico cuidado e este se realiza plenamente, com o que confunde a estrutura ontológica radical com um fenómeno "ôntico", fáctico, em vez de captar a sua originariedade "ontológico-fundamental" como o modo de ser em que o Da-sein como tal, na sua totalidade, ser exerce. Por isso, dirá Heidegger, acremente, que a "análise existencial" de Binswanger não entendeu o essencial da "analítica existenciária", confundindo o fenómeno de superfície (antropológico) com o de fundo (ontológico), e banalizando, à maneira quotidiana do estar-interpretado, o que CUIDAR DE significa: pro-curar fazer pela vida, ocupado à beira dos entes que nos vêm ao encontro, e solícito com os outros, com os que se está a ser-no-mundo:

O cuidado, bem entendido - isto é, à maneira ontológico-fundamental não pode nunca distinguir-se do 'amor', pois não é senão o nome da constituição temporal-ex-stática enquanto traço dominante do Dasein, mais precisamente, a compreensão do ser. [Assim,] o amor funda-se tão decisivamente na compreensão do ser como o cuidado, mencionado em sentido antropológico. ${ }^{7}$

Esta última citação situa o nosso tema num triplo sentido, cuja exposição terá de ser parcimoniosa:

1) porque, procedendo dos encontros, em Zurique, de Heidegger com o gupo de psiquiatras reunido em torno ao suiço Medard Boss, que tiveram lugar entre 1959 e 1969 e foram publicados por este último em 1987, sob o título de Seminários de Zollikon, nos desloca para o que, no meu entender, foi a única aplicação meta-ontológica da análise existencial em que o próprio Heidegger, directamente, se empenhou;

${ }^{6}$ Binswanger, L., Gundformen und Erkenntnis menschlichen Daseins, 1942. 2." ed., Zürich, M. Niehans, 1953.

7 Heidegger, Zollikoner Seminare, [doravante, ZS], Frankfurt, Klostermann, 1987 (2." ed., 1994), 237. Para a crítica a Binswanger veja-se especialmente, 236 ss. e 253. Há uma tradução brasileira: Seminários de Zollikon, ed. de M. Boss, trad. de G. Arnhold e M. F. Prado, Petrópolis, Vozes, 2001, 311 pág. 
2) porque a afirmação vincula indelevelmente o fenómeno ontológico do cuidado - de que se diz em Ser e Tempo que é "o ser do Dasein" ${ }^{-}$ com a questão do tempo, de que os conteúdos lectivos correspondentes ao seminário de 1964/65 dão ampla notícia;

3) enfim, porque o acento ontológico da problemática "hermenêutica" da "compreensão do ser" recolhe e reafirma, nesta data avançada - em que, de um ponto de vista estritamente histórico-filosófico, já não falaríamos nem de Ontologia Fundamental, nem, muito menos, de hermenêutica da facticidade - o carácter central na preocupação heideggeriana daquilo que, na sua produção pública desses mesmos anos, parecia ter ido cedendo o lugar a uma meditação de outro tipo e características, aparentemente afastadas da primeira época da sua filosofia, em que o olfacto agudo e interessado de Löwith encontrara afinidades com a Psicanálise.

Assim sendo, começarei por chamar a atenção para a importância que Heidegger atribui ao diálogo entre a formação basicamente naturalista dos assistentes ao seminário e a perspectiva ontológica que ele pretende introduzir, para mostrar, em seguida, como a existência humana se traduz numa determinada experiência tácita do tempo, reveladora do sentido ou privação de sentido de realidade de cada um e, portanto, do seu ser-no-mundo à beira das coisas, de que se ocupa, sendo com outrem. Finalmente, tentarei indiciar de que modo esta compreensão "do tempo", que não é senão a do próprio ser (do nosso, à maneira do Dasein, e do das coisas, entre as que fazemos a nossa vida quotidiana), adquire possível relevância para a prática terapêutica.

\section{Análise existencial e prática médica}

A aproximação entre o médico Medard Boss e o pensador Martin Heidegger, inicialmente epistolar (1947), afiançou-se em vários encontros pessoais, a partir de 1949, que levaram à concepção e posterior consecussão, entre 1959 e 1969, dos seminários em Zollikon, orientados, segundo confessou o próprio Heidegger, no sentido de "fazer sair os insight filosóficos" da sua torre de marfim, para, fecundamente, "os fazer chegar à multidão de seres humanos necessitados de ajuda". ${ }^{9}$ Mas, para isso, haveria que formar "médicos-pensadores", que não se dediquem apenas a "limpar o campo" para que os "técnicos", cientificamente preparados, campeiem à sua vontade, ${ }^{10}$ antes preparando um diálogo frutífero e solícito com o ser humano que procura ajuda clínica.

${ }^{8} \mathrm{SuZ}, \S 39,180 \mathrm{ss} ; 182$.

9 ZS (1987), XII.

${ }^{10}$ Veja-se ZS, 134 (trad. br. 129). 
A questão fundamental está, pois, na luta contra a ideia da medicina científica moderna enquanto profissão "técnica", isto é, contra a conversão tecnológica da relação médico-paciente, pela qual, a "cura" é o resultado de um processo operativo (medicamentoso ou cirúrgico) ao nível de zonas predefinidas como objecto de intervenção, sem atender ao todo do ser humano, que na sua dignidade de mortal, se vê privado - porque doente - do seu quotidiano poder fazer pela vida. Nesta "privação" manifesta-se uma modificação das dimensões de espacialidade e temporalidade que constituem o ser-no-mundo. Estas duas experiências - do espaço e do tempo - são, pois, especialmente reveladoras do Dasein na sua facticidade.

Pela mesma época, não podemos esquecer, que tanto a psicanálise, a um certo nível, como a recém denominada "psicossomática" procuravam algo semelhante, sem contudo prescindir da fundamentação estritamente científica. Heidegger não deixa de polemizar com ambas as tendências no âmbito psicoterapêutico: com o cientificismo naturalista de Freud, que considera constituir uma "transferência da filosofia neo-kantiana para o âmbito do humano","1 sendo devedora da concepção moderna de natureza, por um lado, e da teoria da objectividade kantiana, por outro; e com concepções como a de Thure von Uexküll - um dos teóricos da Psicossomática - que se, por um lado, critica os "médicos filosofantes" em nome da "consciência crítica" da prática científica, ${ }^{12}$ por outro, admite tacitamente o pre-conceito tradicional que está na base da própria ideia da psico-somática - a separação entre soma-corpo-carne e psyche-alma-mente. Só há que re-unir o que, à partida, se compreende separado, sem que a admissão da inicial separação chegue, contudo, verdadeiramente a ser posta em causa. Contudo, não é aqui o lugar para nos estendermos nesta dupla polémica, mas apenas para registá-la no que, para este nosso percurso, nos interessa: a luta contra a interpretação tácita e ingénua - à maneira da postura natural, de que falava Husserl - que subjaz à investigação científica e à exportação do modelo físico-matemático de medida para o campo objectual da psicologia e da sociologia.

A proposta heideggeriana, aceite e trabalhada por Medard Boss, consistiria em impugnar a concepção naturalista, presente na psiquiatria, psicoterapia e psicologia, que não faz jus ao humano no seu ser-humano, vendo-o como qualquer otro objecto natural, para procurar numa via ontológica filosófica a fundamentação daquilo a que chamarão Daseinsanalyse e concebem como "a comprovação e descrição em cada caso fáctica dos fenómenos que se mostram num determinado Dasein existente". ${ }^{13}$

Esta "análise existencial" distingue-se da "analítica existenciária", levada a cabo em Ser e Tempo, porque, embora fundando-se nesta e guardando

$11 \mathrm{ZS}, 260$.

12 ZS, 133-134.

13 ZS, 163: "Daseynsanalyse im Sinne des Nachweisens und Beschreibens jeweils faktisch sich zeigender Phänomene an einem bestimmten existierenden Dasein..." 
as estruturas fundamentais nela postas a descoberto - a saber, as estruturas da ex-sistência e da correspondente projecção do horizonte de encontro com as coisas - se move no âmbito meta-ontológico do concreto, do ente facticamente existente, com as características e formas de manifestação em cada caso próprias. A "analítica" do Dasein, em sentido ontológico, desvela o fenómeno básico do ser-em (um mundo) enquanto compreender afectivo articulado em discurso (befindliches Verstehen + Rede) e sempre já de antemão tendente a decair no estender-se prolongado do entender à maneira habitual, segundo o que se diz, segundo o que nos é dado já interpretado. Em forma própria ou imprópria, este projecto de sentido, que faz mundo em cada instante, aguarda o vindouro e guarda o que passou (recordando, mas também esquecendo) na expectativa do seu fazer-se presente em cada instante. Ou seja: ser-o-aí é o abrir-se ex-stático do tempo, projecção instantânea do sido no porvir e introjecção no aberto enquanto horizonte de encontro.

Este projecto lançado de sentido é, pois, simultaneamente, a própria existência e história: o exercício quotidiano dọ ocupar-se cada um com os entes à sua beira e com outrem e o acontecer histórico do que, assim, em cada um e em todos os seres humanos se dá. É a este todo - a totalidade do ser do Dasein - que Heidegger chama "cuidado", Sorge: uma inquietude pre-ocupada com o mundo e as coisas intramundanas, que ao manifestar-se faz-mundo, tornando presente o que se guarda e aguarda num exercício constante de acolhimento e luta, de descoberta e encobrimento. Em Ser e Tempo este todo exprime-se formalmente do seguinte modo:

Die Seinsganzheit des Daseins als Sorge besagt: Sich-vorweg-schon-seinin (einer Welt) als Sein-bei (innerweltlich begegnendem Seienden). ${ }^{14}$

A totalidade do ser do Dasein enquanto cuidado quer dizer: ser-se-antecipadamente-já-em (um mundo) como ser-à-beira-de (os entes que vêm-ao-encontro dentro do mundo).

Como é que esta "inquietude" pelo próprio ser e pelo ser de tudo o que não é à maneira do ser próprio, como é que esta abertura porosamente antecipativa e palpitantemente instantânea pode abandonar-se ao presente, àquilo de que se está "à beira" (bei)? Como é que a inquietude se esconde e descansa no enleio do trato quotidiano com as coisas? Como é que se pega e adere ao que está imediatamente aí-à frente, à nossa mão e alcance vital?

Para Heidegger, esse deter-se no mero presente, enganando a angústia em que a suspeita de finitude se traduz, é o decair na inautenticidade ôntica, é o esquecimento do que mais importa. Ora, esse decair é, no entanto, o que, em geral, mais claramente preserva de adoecer! A plena autenticidade do cuidado, sempre em transe de um futuro denso de passado, não só cansa, esgota. 
Só é vivível por momentos. O angustioso manter-se "instado" não é sustentável indefinidamente. Por isso, o tempo do mundo - impróprio mas vivível é o do agarrar-se ao presente, evitando antecipar ou recordar o que angustia: o ausente sem figura.

Recordemos aquela cançoneta que, numa voz bastante monocórdica, se ouvia repetidamente em toda a parte há alguns anos: "Dont'worry. Be happy." . A quotidianeidade foge da autenticidade para não adoecer: agarra-se às coisas familiares, também aos outros entes humanos, com os que convive e que até pode amar, para poder esquecer o que perturba.

Nesta descrição, que parte dos parágrafos fundamentais de Ser e Tempo ( $\S 41$ e 65), desenha-se a uma hermenêutica fenomenológica do humano, que nos Zollikoner Seminare se estende à problemática do enfermar, isto é, ao fracasso da existência inautêntica. O que significa que o estar-doente pode ser, no seu sofrimento, a manifestação mais plena do ser à maneira do Dasein - essa plenitude que o dia-a-dia, justamente, esbate e evita.

\section{O tempo do cuidado e o tempo do mundo}

O ser humano atém-se ao que lhe diz respeito. Está ligado às coisas e aos outros. As coisas inanimadas são representadas desde antanho como estando no espaço e no tempo. Ora o homem está no espaço e no tempo de outra maneira completamente diferente, pois o ser humano é ele mesmo espacial e temporal. Ao traduzir o ex-sistir por estar-para-fora, digo-o em contraposição a Descartes, contra a sua representação da res cogitans no sentido duma imanência. Mas ao fazer esta contraposição ponho-me em companhia dos antigos. ${ }^{15}$

Ser à maneira do Dașein é existir e ex-sistir é estar em cada instante à pro-cura do que há-de vir e actualizar-se, preparado pelo vivido: ou seja, estar-para-fora (e não estar em si mesmo, em auto-afirmação autofágica). O tempo do cuidado é o da procura. Mas as coisas tornam-se-nos presentes, isto é, presentificam-se: a sua modalidade de se dar no tempo, que é o nosso - no sentido do actual aguardar e guardar - é a do presente, Gegenwart. Presente indica, aqui, que a coisa está aí-diante, à mão dentro do mundo para um fazer dela uso (segundo o esquema do $u m z u$ ), ${ }^{16}$ ou como objecto de observação ou estudo. Esse ser-presente [gegenwärtig] do que está-presente [anwesend] no mundo é, pois, inteiramente diverso do que chamamos "instante", Augenblick. À presença estática e demorada das coisas ante nós retidas, contrapõe-se o inquieto palpitar próprio do Dasein: nunca "em presença", sempre em cada caso em "êxtase". No entanto, residir ex-sistindo à beira dos entes intramundanos é actualizar, de cada vez, a sua presença expectada, mesmo quando esquecida. 
Esta diferença fundamental entre o tempo das coisas e o tempo do Dasein que as procura e torna presentes - seja na atenção directa e perceptiva, seja na recordação ou na expectativa - constitui a base da compreensão heideggeriana do fenómeno do cuidado, enquanto dinâmica temporal. A essa diferença é inerente uma característica: tudo o que se torna presente aparece como "algo" aí-à-frente, como intra-mundano. Enquanto que o Dasein faz mundo, projectando sentido, o mundo aparece como o conjunto das coisas que nele - lá dentro - se encontram. A dinâmica estruturante do ser-em cristaliza num horizonte mundano de entes e funções ônticas, de que nem sequer os humanos estão isentos. Até a própria estrutura estruturante se coagula em objectividade. Assim surge a compreensão habitual e objectiva do tempo intramundano, marcado pela presença sequencial de "agoras" isomorfos, que o cronómetro mede com precisão infinita. O tempo das coisas, nascido do tempo do Dasein, reduz-se então - questão, por outro lado, importante na Fenomenologia husserliana - ao tempo objectivo do relógio, que é entendido ele mesmo à maneira de "coisa", susceptivel de medição e cálculo. Deste, diz Heidegger que é uma modificação do tempo do mundo: o ser-no-tempo, ter ou não ter tempo para algo. Desta concepção vulgar, naturalista, até a ciência se faz eco. Cronometria, cronografia, cronologia são designações inerentes a diferentes ciências positivas, que partem da aceitação tácita do tempo como "algo" natural, físico ou histórico, susceptível de ser medido e situado.

De que devemos, então, falar, se procuramos compreender a perturbação da relação com o real do ser humano doente? Do tempo do Dasein (a temporalidade ex-stática no seu carácter sempre triádico), do tempo do mundo (o indefinido alargar-se do presente em que as coisas nos vêm ao encontro dentro do mundo) ou do tempo cronológico (a intratemporalidade de tudo o que se situa no fluxo dos agoras)? Nos Seminários, Heidegger, limita-se reflectir sobre o tempo do mundo, pois é no trato quotidiano com as coisas que se vê alterado o comportamento do Dasein.

\section{III. "O tempo até ver aprazado assoma no horizonte"}

A problemática do tempo não é a primeira a aparecer tratada nos seminários. Antes de se concentrar nela, nas sessões de 1964/65, Heidegger tratou da questão do espaço e da significatividade do mundo, introduzindo pela via hermenêutica anti-naturalista a temática da "relação ao mundo" (Weltbezug), que em Ser e Tempo aparecia primordialmente como "ser-em". É com esse fio de meada que começa, como já fizera em 1924, na célebre conferência sobre "O conceito de tempo", pela consideração do tempo do relógio. ${ }^{17}$ 
A relação mais imediata do ser humano com o tempo é a que parte da contagem do tempo e do que ela permite: saber "a quantas andamos", ter ou não ter tempo para algo, chegar ou não chegar a tempo para fazer alguma coisa ou encontrar-se com alguém nalgum sítio, poder combinar encontros. No entanto, esta relação não pode ser a mais originária, pois para poder fazer estes cálculos temos que pressupor que "o tempo" está de antemão dado (é o que o relógio mede). O preciso momento temporal reporta-se ao agora (Jetzt), em que temos algo presente; ou a antes (Damals), em que retivemos o acontecido; ou a um depois (Dann), que aguardamos expectantes. Estas três dimensões podem aparecer também como hoje, ontem ou amanhã, presente, passado ou futuro. Mas, em qualquer caso, contar com o tempo pressupõe que há tempo, que o tempo está dado, previamente ao poder medi-lo e usá-lo. Heidegger traduz esta experiência dizendo que "não há dados temporais (Zeit-Angabe) sem um prévio dom do tempo (Zeit-Gabe)" ${ }^{18}$ É no aprofundamento deste "dom do tempo", que passa desapercebido no exercício do quotidiano fazer pela vida, que se vai desvelar o sentido de "ter o tempo".

Ter ou não ter tempo diz-se, sempre, a propósito de algo: é um "tempo para..." que aponta numa determinada direcção: para fazer isto ou para que se passe aquilo. A esta primeira característica chama Heidegger a Deutsamkeit - em SuZ, § 80 dizia: Bedeutsamkeit! - que vamos traduzir como o "apontar para", em que se denota não a intencionalidade de um sujeito, à maneira husserliana, mas o carácter de significação do próprio tempo: "die Deutsamkeit gehört zur Zeit selbst", ${ }^{19}$ é-lhe inerente a plenitude de sentido, percebida pelo Dasein em cada caso como a "hora de": o "tempo aprazado" dos "dias difíceis" que "assoma no horizonte", como canta Ingeborg Bachmann num dos seus poemas. ${ }^{20}$

A segunda característica é a da datação (Datiertheit), a experiência do tempo como a "data" em que algo se passa, ou passou ou passará. Não tanto no sentido do calendário, mas no do estar-dado do tempo: agora, que estamos aqui ou logo, quando nos formos embora, ou antes, quando preparava este paper. Ou o dia em que nasceu a menina. Ou o dia de festa.

A terceira característica liga estas duas, pois estes três momentos não expressam o tic-tac de um relógio, não são meros pontos idênticos entre si

18 ZS, 53. Veja-se tb, 52: "Beim Auf-die-Uhr-Sehen beschäftige ich mich zwar mit der Zeit, aber im Hinblick auf ein Wieviel an Zeit. [...] Wir können nur eine Uhr gebrauchen weil es für uns vorhine in ein Heute, ein Morgen, ein Gestern gibt."

$19 \mathrm{ZS}, 54$

${ }^{20}$ Veja-se a belíssima edição bilingue de João Barrento: Bachmann, Ingeborg, O tempo aprazado, Lisboa, Assírio e Alvim, 1992, 40-41: "Vêm aí dias difíceis. / O tempo até ver aprazado / assoma no Horizonte / Em breve terás de atar os sapatos / e recolher os cães nos casais da lezíria, pois as vísceras dos peixes/ arrefeceram ao vento. / Mortiça arde a luz dos tremoceiros. / O teu olhar abre caminho no nevoeiro: / o tempo até ver aprazado / assoma no horizonte. / [...] Não olhes em volta. / Ata os sapatos. / Recolhe os cães. / Lança os peixes ao mar. / Extingue os tremoceiros / Vêm aí dias difíceis." 
e sem extensão. O agora ou o logo têm uma "amplitude temporal" (zeitliche Weite) própria e variável: "em breve terás de atar os sapatos e recolher os cães nos casais da lezíria..." Esta amplitude pode ser a da conversa no café ou a do inverno passado. É um tempo rico, denso de vida, "onde" algo acontece ou se dá, que nos afecta.

Finalmente, uma quarta dimensão completa a descrição da experiência fenomenológica do tempo que se tem, com que se conta: "o agora que, datado, aponta para, estendendo-se também não é nunca um agora que só esteja ligado a mim". ${ }^{21}$ Este tempo é público, só me é acessível no ser com outros, no desempenho mundano do conviver quotidiano, em que, decaindo, tendemos a deixar-nos ir e arrastar pelo impessoal.

O tempo do mundo aparece, pois, como um tempo vivido e pleno, em que as 3 dimensões do tempo ex-stático do Dasein (em sentido próprio ou impróprio) e a tendência para a queda se reconhecem enriquecidas no exercício fáctico do viver concreto de cada um, no seio do seu mundo circundante. Passado, presente e futuro significam, no nosso dia-a-dia, datas festivas e significativas, expectativa de encontros e realização de tarefas, momentos de paz e de inquietude, tempo de saldos e de trabalho. É sobre esta base que há que compreender a experiência patológica do tempo. ${ }^{22}$

\section{A experiência patológica e o tempo}

Que acontece quando o ser humano perde a capacidade de viver com os outros no tempo que é de todos, que é tempo de encontro e de realização, de amor e de trabalho, de cuidado e de descuido? Heidegger só toca de leve a questão, o que é pena, mas se compreende porque a prática dos assistentes ao Seminário é, certamente, mais experiente que a sua nesse campo. Contudo, centra a reflexão, tomando como ponto de partida a noção de "doença" como "privação".

Fiel à sua compreensão da fenomenologia como caminho de mostração da coisa ela mesma na linguagem, procura explorar o alcance da expressão "ter" ou "não ter" tempo para algo. E sublinha que aquilo que mencionamos ao dizer "ter tempo" se aclara através da expressão contrária: "não ter tempo". Que tipo de negação é esta? Certamente, não é de tipo lógico, não é uma negação absoluta e sem mais [schlechthin], mesmo que as expressões possam integrar frases e proposições susceptíveis de uma análise desse tipo. Para explicitar o tipo de negação que aqui aparece, Heidegger utiliza o termo Verneinung, que poderemos traduzir como denegação, embora, no contexto psicanalítico, o célebre texto de Freud com esse título costume traduzir-se sim- 
plesmente como "negação". Tal como para Freud - que não aparece para nada nesta exposição heideggeriana - o que a denegação põe de relevo é a prévia e sub-reptícia afirmação do (agora) negado: não ter tempo significa que se conta com "ter" tempo, um tempo que pode faltar-nos, não chegar para o que quer que seja, ser-nos arrebatado. Este sentido da negação traduz o fenómeno ontológico da privação: "uma possibilidade do ser, e não meramente relativa ao carácter lógico de uma expressão negativa, com a qual nos encontramos amiúde na consideração do fenómeno tempo". ${ }^{23}$ E é neste contexto que surge a definição heideggeriana de um estado patológico.

O curioso é que toda a profissão médica se move no âmbito de uma negação no sentido de privação. Pois o certo é que tem que tratar com a doença. O médico interroga quem o procura acerca daquilo de que se queixa. Doente é quem não está são. O ser saudável, o bem estar ou sentir-se não desapareceu, pura e simplesmente, só está perturbado. A doença não é a mera negação do estado psicossomático. A doença é um fenómeno de privação. Em qualquer privação reside o pertencer, segundo a essência, àquilo a que falta algo, àquilo que perdeu. Isto parece uma trivialidade, mas é bestialmente importante, pois é, justamente, o âmbito em que a vossa profissão se move. Porque têm a ver com a doença, têm a ver com a saúde, no sentido de que falta e há que reavê-la. ${ }^{24}$

A ciência não tem suficientemente em consideração este carácter de privação, sendo capaz de mencionar a matéria, por ex., como "natureza morta". Ora, "morto" só está o que pode morrer, isto é, o que vive. A matéria não é algo morto, mas inanimado. Em contrapartida, este fenómeno foi bem reconhecido em Filosofia, desde Platão que, no Sofista, elucidou, em resposta a Parménides, que nem tudo o que não-existe pura e simplesmente não-é. Neste sentido, tal como a sombra, por ex., não é senão a falta de luminosidade; tal como a verdade, para o sentir grego, a aletheia, não era senão o "não-estar-encoberto"; assim também "o não estar são, o estar doente - diz Heidegger - é uma modalidade privativa do existir". ${ }^{25}$ A privação não é, pois, nem mera negação, nem carência, precisão de outra coisa, mas apenas remissão em ausência a uma presença prévia, que, justamente, se ausentou.

Em que é que isto nos ajuda a compreender a vivência patológica do tempo? Ter e não ter tempo são experiências quotidianas, que podem ser ou não vividas doentiamente. A angústia ante o resultado de um desempenho, em que me sinto insegura, não é em si mesma enfermiça. Sim, em contrapartida, o estado de angústia contínuo, sem aparente motivo. $\mathrm{O}$ inquieto cuidar do porvir

25 ZS, 59: "Ein solches Nicht-Seiendes im Sinne der Privation ist z.B. der Schatten, insofern er ein Fehlen von Helle ist. So ist auch das Nichtgesundsein, das Kranksein, eine privative Weise des Existierens." 
faz parte do exercício de ser à maneira do humano. Mas um futuro angustiosamente desejado ou temido pode levar a evitar o desejo ou temor, fazendo que me atenha só ao mero presente, em que me agarro às coisas e tarefas familiares, que me tranquilizam, ocupando-me. Dont'worry, be happy... A terapia ocupacional usa bem essa experiência. É, nesse caso, o porvir que se apraza para mais tarde. Freud, por outro lado, falara do recalcamento como o que eu traduziria aqui como a memória indelével do esquecido. Porque, na verdade, não está esquecido, mas apenas encoberto, sendo revivido com cada pretexto, repetido com uma força que recorda a situação traumática inicial. O passado não passou: torna-se presente, sem contudo aparecer como tal recordação, isto é, como se fosse algo passado. Presentia in absentia.

Reflectir sobre esta questão constitui o último passo da nossa meditação.

\section{O tempo ex-stático no encontro terapêutico}

O psicanalista francês André Green numa conferência de 2005, recentemente publicada, chama a atenção para a originalidade da noção freudiana do nachträglich, ${ }^{26}$ do carácter recessivo das representações recalcadas, que, à maneira do cavalo no jogo de xadrez, salta por cima das filas do tabuleiro, ladeando, para trás ou para a frente, o impecilho, sem respeitar uma ordenação segundo a ideia corrente - Heidegger diria "vulgar" - do tempo, como uma sequência direitinha de passado-presente-futuro.

O mesmo autor, com uma acuidade que vai muito além do mero estudo da contribuição de Freud e da prática da Psicanálise até aos nossos dias, e pondo a descoberto aspectos que Freud, certamente, nem suspeitou, termina brilhantemente a sua exposição reflectindo sobre o tempo da e na própria sessão de análise, caracterizando o que designa por "investimento lateral" (lateral cathexis). Parte da cadeia associativa do paciente, para chegar, penso eu, à do analista que atende. $\mathrm{O}$ analisando percorre um estranho caminho saltitante, mediante o qual vai revelando, de forma lateral, não só indirecta mas também com avanços e recuos, com saltos que fogem à racionalidade lógica, os laços entre diferentes temas, todos eles imbricados de forma indefinida mas indelével. Não fala de manobras dilatórias, de desvios de tempo e espaço. Mas deixa-nos supor que existem... como elemento fundamental do processo de apropiação temporal do sentido. E aqui, neste ponto, com uma magnífica pirueta, André Green salta, também ele, para o ponto de vista do analista na análise, para, referindo-se ao tempo, com a sua - dele - linguagem exprimir o que, creio, Heidegger queria dizer com o carácter ex-stático do tempo do Dasein:

Tentei descrever como o tempo, na sessão, funciona. Acho que o analista no seu trabalho presta atenção e, de repente, compreende que tal elemento, per- 
tencente a uma cadeia associativa, tem conexões indirectas com um elemento anterior, que ouvira. A isto eu chamo reverberação retrospectiva [retrospective reverberation]. Mas, por outro lado, o analista vai ouvindo e ouvindo algo que ele prevê como um anúncio de que o paciente vai falar disto ou daquilo, o que é uma associação prospectiva a que eu chamo antecipação anunciadora [heralding antecipation]. O que cada um tem que compreender é que a linearidade da associação não tem importância nenhuma. O que importa é a conexão que pode ser feita para trás e para a frente. Chamo a isto radiação associativa [associative radiation]. Há que prestar atenção ao movimento, à irradiação dos significantes e à maneira como conecta os significantes quer com os traumas, quer com memórias e afectos anteriores. [...] Todo este movimento é um movimento de separação, de encontro, de se aproximar do analista e de se afastar dele. É a isto que chamo movimento. Se tentarmos conjuntar o que disse durante esta hora, vemos que há uma oposição entre sistema representativo e sistema motor - de movimento. É que, de facto, há uma extinção da temporalidade. ${ }^{27}$

Deixando à margem a questão específica da sessão analítica e do encontro, nela, de analista e analisando no seu percurso comum, esta leitura do tempo é a que Heidegger avança ao falar de temporalidade ex-stática. A "reverberação retrospectiva" é um salto atrás, mas não para um ponto fixo: o salto é englobante do(s) terreno(s) sobre os quais salta e que ficaram guardados na memória inquieta do analista, porque apareceram em diferentes momentos do que ouviu dizer. A "antecipação anunciadora” é o aguardar expectante de uma ligação com algo prévio, mais impulso que mera representação, procedente do fluxo de recordações e fantasias, mas também reflexões, que surgem no contexto associativo da análise, como tempo suspenso do tempo real do mundo, embora guardando-o simbolicamente. E a "radiação associativa" é a uma designação pregnante daquilo que é $o$ instante em que o sido e o vindouro estalam numa cintilação em que a amplitude e o ponto concreto, a que o tempo aprazado e datado aponta, se tornam públicos, numa fulguração em que, por fim, talvez dissimulada mas até por isso mais inequivocamente o todo de sentido aparece. É interessante notar que, numa concessão ao conceito habitual de tempo, como sequência linear, o próprio autor termina, após uma contraposição entre o sistema representativo e o movimento do pensar, por considerar que há uma "extinção da temporalidade", quando o que, realmente, acontece é que o tempo da representação tem o carácter da presença e, portanto, da passagem contínua, enquanto que o tempo ex-stático, que Green menciona como "movimento", se realiza de forma palpitante e irradiante, rompendo o contínuo das sucessivas presenças, sem contudo deter, de nenhuma maneira, a mobilidade do pensar. Aquilo a que chama "extinção da temporalidade" parece-me ser, justamente, o salto a um sentido mais originário do tempo inerente ao ser à maneira do humano. 
$\mathrm{Na}$ linguagem heideggeriana - da Hermenêutica da Facticidade que é a Ontologia Fundamental - tratar-se-ia, afinal, da sempre afectiva compreensão que chega à palavra, em que o correr ao encontro do que se teme, repete ou retoma o que em cada instante se cala, queira-se ou não. Quer isto dizer, para ir terminando, que as três dimensões do tempo, junto com a $4 .{ }^{\mathrm{a}}$ (o tempo decaído do público), não têm nada de sequencial mas de simultâneo. Passado, presente e futuro são ao mesmo tempo, o mesmo tempo pulsátil do Dasein. Têm igual originariedade..$^{28}$

Umas vezes prevalece uma, outras outra dimensão, a que nos entregamos e em que, talvez nos deixemos prender. Mas as restantes dimensões não desaparecem, apenas se modificam. As outras dimensões não sucumbem a uma mera negação, mas a uma privação. ${ }^{29}$

É certo que esta leitura não explica muitos comportamentos. Mas permite compreender fenómenos que Freud pensava que manifestavam um alheamento da temporalidade, que eram, digamos, "atemporais". Como os sonhos! Lido a partir da ontologia hermenêutica não só não são atemporais, como revelam o puro brotar simultâneo e co-originário das três dimensões ex-státicas do tempo ${ }^{30}$ marcando a característica mais própria do Dasein, a sua irredutibilidade à mera presença, à maneira das coisas, no horizonte de sentido figurado como realidade.

Faltar-nos-ia, neste percurso, aplicar estes princípios de leitura a casos concretos da vida quotidiana, sadia e insã. Não é já possível chegar a esse ponto, inicialmente almejado. Ficará para outro momento, dando continuidade a este.

Baste-nos, por ora, para terminar, recordar que para Heidegger, pelo que creio ter ido deixando claro na exposição difícil do fenómeno existencial e existenciário do tempo, que a perda do sentido de realidade e da sua experiência partilhada do tempo, a privação do relacionamento são com as coisas e os outros com que fazemos pela vida no residir quotidiano no mundo, não tem menos dignidade ontológica que a do comportamento são. Talvez até tenha mais, roçando o cume do máximo perigo, por abdicar, privando-se, daquilo que permite, no dia-a-dia, o embotamento da inteligência sentinte - a expressão é de Zubiri - e, sem a impedir de palavra, a deixa diluir-se no palavreado banal da vida pública.

${ }^{30}$ Analisei este fenómeno a propósito do sonho de Descartes em Borges-Duarte, I.: "O melão, o remoinho e o tempo. Descartes e o sonho de uma noite de outono". Revista Portuguesa de Filosofia (Braga) 59, 2003 (Fasc. 3, monográfico: Filosofia e Psicanálise), 315-337. 


\begin{abstract}
This paper seeks to understand Heidegger's phenomenological analysis of the time experience in Sein und Zeit, from the formal point of view of the Care-structure, and in the Seminars of Zollikon, where time is described as world-time in its fullness. Aimed is to show that the early anthropological reception of his major work of 1927 by some of his pupils, like Löwith, who detected similarities with Psychoanalysis, is somehow strengthed by Heidegger himself later on, as he comes with Medard Boss to develop Daseynsanalysis as a metaonlogical understanding of humans life in health and pathology. Illness as privation of health will be seen as the failure of inauthentic existence. And the full, ecstatical experience of time will be shown as the proper or authentic one, being-in-the-world as well as within the psychoanalytical session and interpretation.
\end{abstract}


